\title{
Explaining Attitudes toward Immigration: The Role of Regional Context and Individual Predispositions
}

\author{
JOHANNES KARRETH, SHANE P. SINGH and SZYMON M. STOJEK
}

\begin{abstract}
Existing research makes competing predictions and yields contradictory findings about the relationships between natives' exposure to immigrants and their attitudes toward immigration. Engaging this disjuncture, this article argues that individual predispositions moderate the impact of exposure to immigrants on negative attitudes toward immigrants. Negative attitudes toward immigration are more likely among individuals who are most sensitive to such threats. Because country-level studies are generally unable to appropriately measure the immigration context in which individuals form their attitudes, this article uses a newly collected dataset on regional immigration patterns in Austria, Germany, and Switzerland to test the argument. The data show that increasing and visible diversity is associated with negative attitudes toward immigrants, but only among natives on the political right. This finding improves the understanding of attitudes toward immigrants and immigration and has implications for the study of attitudes toward other policies and for immigration policy itself.
\end{abstract}

The relationship between the presence of immigrants and citizens' attitudes toward immigrants and migration policies is uncertain and frequently debated. One perspective represented in many studies suggests that 'an increase in the percentage of ethnic minority members ... reduces the majority's prejudice' (Wagner et al. 2006: 380). Another group of studies contradicts this finding, as exemplified by Quillian (1995: 602): 'prejudice is more likely when there is a large foreign presence'. These divergent findings align with the competing predictions from theories of natives' attitudes towards immigrants. Ethnic competition theory and realistic group conflict theory see exposure to outgroups, especially those from ethnically and culturally distinct origins, as leading to anti-immigrant attitudes among natives (Quillian 1995). Conversely, intergroup contact theory (e.g. Allport 1954) argues that larger outgroup populations can engender positive attitudes, although the eponymous 'contact' mechanism takes time to develop and its benefits are conditional on relative socioeconomic equality. On a different

Correspondence Address: Email: jkarreth@albany.edu 
analytical dimension, many recent studies have investigated two key drivers of attitudes to immigration mostly separate from each other. Work on contextual effects in the form of geographic or social patterns typically measures the impact of migrants' presence on natives' attitudes (e.g. Bowyer 2009). Other studies have focused on individual-level factors and predispositions as determinants of attitudes toward immigration (e.g. Hainmueller and Hiscox 2007). Studies considering both contextual and individual determinants of attitudes to immigration typically treat them as competing explanations (e.g. Sides and Citrin 2007).

Taking these contrasting expectations and findings as our point of departure, we argue in this article that a complete model of the formation of attitudes to immigration should treat contextual effects as conditional on individual-level predispositions of attitude holders. Extant research leads us to expect that, while people in areas with traditionally high levels of immigration may be more accepting of immigrants, influxes of newcomers who are socioculturally different from natives will heighten perceptions of cultural and economic threat and will result in negative attitudes toward immigrants. We expand this model, arguing that the effects of the presence and inflow of immigrants on attitudes to immigration are conditioned by individuals' proclivities to perceive outgroups as threatening. In particular, we consider individuals' ideological orientations, noting that the hypothesised contextual effects should be most pronounced among those on the political right, who are especially sensitive to threat from outgroups. Our conditional argument advances the literature examining citizens' attitudes toward immigrants and suggests an explanation for why previous work has found support for both positive and negative effects of exposure to outgroups.

We test our expectations in a cross-national framework before employing more fine-grained data. Our analyses initially demonstrate that aggregate, national-level data are unable to reveal our hypothesised patterns. We then move to analyses of original regional data on immigration patterns across three European countries, suspecting that more fine-grained data map the theoretical mechanisms behind exposure and perceived threat more appropriately. The results indicate that natives living in regions with traditionally high immigration levels tend to be more acceptant of immigrants. Second, recent boosts in immigration levels and a prevalence of immigrants from socio-ethnically distant and less economically developed nations is associated with lower acceptance of immigrants, but only among natives on the political right. As the overwhelming majority of recent immigration into Western countries is from socio-ethnically dissimilar and economically poorer countries, our findings have broad importance for social relations, civic community, and the dynamics of integration.

\section{Immigration, Diversity, and Attitudes: Existing Literature}

Extant theories make contradictory predictions about the effect of exposure to outgroups on ingroup attitudes. First, intergroup contact theory argues that repeated exposure to an outgroup may breed acceptance of others. Increasing 
familiarity through contact not only decreases prejudice (Wagner et al. 2006), but may also increase 'friendship potential' (Pettigrew 1998). Such effects, Allport (1954) argues, are most likely to surface when different groups enjoy relatively equal status and intergroup threat and competition are low or absent. Still, more recent research shows that contact even in potentially conflictual settings, such as schools and workplaces, can improve cross-group attitudes, as can purely casual acquaintances (Bourgeois and Friedkin 2001; Welch and Sigelman 2000). Further, merely observing cross-group contacts of others can decrease one's propensity to cast negative stereotypes (Wright et al. 1997). A meta-analysis of 551 studies conducted in 38 different countries found evidence for a significant negative effect of intergroup contact on social prejudice in over 90 per cent of the studies sampled (Pettigrew and Tropp 2008). Further, focusing on immigration, Schneider (2008) and Ellison et al. (2011) each find that intergroup contact or personal relationships with immigrants can increase the acceptance of immigrants among natives, with Schneider (2008: 60) noting that people who experienced intergroup contact feel 'less threatened by immigrants than others'.

Still, arrivals of non-natives and resulting competition over resources and values can be perceived as a threat to natives' economic well-being and the native culture, which, in turn, can foment anti-immigrant attitudes. Ethnic competition theory predicts that negative attitudes will arise when a sizeable outgroup poses a threat to the cultural status quo, introducing competition over customs, values, and identity (Huntington 2004; Lucassen and Lubbers 2012; Schneider 2008; Zolberg and Woon 1999). Repeated involuntary interaction with immigrants under such conditions will heighten intergroup tension, cancelling out any potentially positive effects of intergroup contact. Arguing from an economic perspective, realistic group conflict theory puts forth that intergroup conflict and anti-outgroup sentiment come about when groups compete over limited resources (Sherif et al. 1961), and this is especially true when competition over resources is severe (Citrin et al. 1997; Sniderman et al. 2004). Such competition has been shown to influence individuals' attitudes to immigration (e.g. Mayda 2006).

In summary, perceived outgroup threat can be economic or cultural in character. The proposed relationship, according to ethnic competition theory and realistic group conflict theory, is that larger outgroups (immigrants) relative to ingroups (natives) will generate cultural and economic threats - and, in turn, negative attitudes. Alternatively, intergroup contact theory suggests the opposite effect, where positive attitudes develop as immigrants and natives interact over time in less threatening settings. Building on these predictions, we seek to enhance and systematise the existing understanding of how the immigration context influences nativist attitudes.

\section{The Context of Immigration, Predispositions, and Attitudes}

We note that the effects of contextual factors vary across individuals according to their perceptions of the contextual stimuli, and we propose that an approach 
which integrates the immigration context and individual proclivities will lead to a more powerful model of attitude formation among natives. Such an approach should account for the nature of immigration inflows, both crosssectionally and over time, and should further consider the predispositions of individuals who are exposed to immigration in varying contexts.

\section{Immigrant Stock and Influxes}

Existing theories suggest that attitudes toward immigrants and immigration are a function of the length of exposure and the degree to which one feels threatened by immigration. Several studies note that outgroup size captures both ethnic threat and potential for intergroup contact (Hopkins 2011; Lucassen and Lubbers 2012; Schneider 2008; Wagner et al. 2006). Thus, a larger immigrant group can increase the incidence of contact between natives and newcomers, reducing prejudice and the perception of threat. A larger immigrant population, however, can also increase the perception of threat as its economic and cultural presence expands vis-à-vis natives. Previous research suggests that both mechanisms are possible in Western societies (cf. Schlueter and Wagner 2008; Schneider 2008; Wagner et al. 2006).

Where overall levels of diversity are pronounced due to historically high immigration inflows, an acceptance of immigrants may come about via repeated exposure. As the acceptance-engendering mechanisms put forth by intergroup contact theory take time to develop and are more likely to be realised once immigrant groups have reached a similar socioeconomic status as natives, it is likely that acceptance-increasing effects outlined in intergroup contact theory will only take hold where high immigration levels are not a new phenomenon.

Where immigration levels have only recently risen, such mechanisms are less likely to have had time to materialise. Instead, where immigration proceeds rapidly and where immigrants may threaten the status quo with a perceived challenge to the economic and cultural well-being of natives, perceptions of immigration threat are likely to surface (Newman and Velez 2014). As a result, negative views of immigrants and immigration are likely to emerge. Natives who are only recently exposed to immigrants in large numbers will not have had time to experience prejudice-reducing contact with an immigrant outgroup. This is a scenario where the acceptance-reducing mechanisms of ethnic competition and realistic group conflict theories are likely to emerge. Work by Coenders and Scheepers (2008) and Hopkins (2010) suggests that negative reactions to immigrants are most likely in response to competition from recent foreign arrivals, rather than existing ethnic diversity.

Competition and contact can thus be at work simultaneously: the former through threats to the status quo and the latter through repeated exposure. Historical levels of diversity and recent immigrant inflows capture these respective 
mechanisms. Our first two hypotheses refer to these mechanisms in summarising the general findings of previous work:

H1: Higher stock levels of immigrants positively influence attitudes towards immigrants and immigration. [Repeated exposure mechanism.]

H2: Recent inflows of immigrants negatively influence attitudes towards immigrants and immigration. [Threat to status quo mechanism.]

\section{Immigrant Characteristics}

Apart from the volume of immigration, the cultural and economic characteristics of incoming immigrants may also exert an effect on natives' attitudes. Outgroup threat is generally considered as a composite of interest-based (economic) and identity-based (cultural) threats (Semyonov et al. 2006; Sides and Citrin 2007). Economic threat is often felt through labour market competition: immigration can affect wages and job security by increasing the available workforce (Citrin et al. 1997; Mayda 2006; Scheve and Slaughter 2001). A second source of economic threat is the burden presented by immigrants who consume public resources (e.g. education, welfare), but have had little time to contribute to the tax revenues that fund these benefits. This is compounded by the fact that, as perceived by natives, immigrants rely on redistributive programmes relatively often - although evidence for this pattern only holds for low-skilled migrants, if at all (Boeri 2010). It is thus likely that the extent to which natives experience economic threat will depend on the economic and professional status of immigrants (Hainmueller and Hiscox 2010).

Cultural threat arises as a result of an ingroup's perception of a challenge posed by the ethnicity, symbols, or values of outgroups (Brewer 2007), which are often assigned an inferior status (Tajfel 1981). Where immigrants are socio-ethnically different, their arrival will discernibly alter the socio-ethnic structure of society. It is influxes of these types of immigrants that are likely to elicit a perceived cultural threat among natives (Leiken 2005). For example, in Switzerland, immigration from European countries such as Austria or Germany will do less to alter attitudes than inflows of immigrants from African or Asian states, who differ comparatively more from the native Swiss in terms of ethnic heritage (see e.g. Semyonov et al. 2006). Indeed, migrants perceived as 'more different' elicit more hostile responses in naturalisation referenda in Switzerland (Hainmueller and Hangartner 2013).

With regard to the characteristics of immigrant populations, and the resulting perceived threat from outgroups, we summarise the literature in the following hypothesis:

H3: Immigration from culturally distant and economically poorer origins (as compared to those of natives) negatively influences attitudes towards immigrants and immigration. [Outgroup threat mechanism.] 


\section{The Role of Political Ideology}

These context-driven expectations are, we argue, only a part of the picture. Depending on natives' attitudinal predispositions, threats from the presence of migrants may appear more or less dramatic, and such threats will thus elicit varying responses to immigration. This conditioning role of individual predispositions is a potential reason for conflicting findings on the effects of immigrants' presence on individual attitudes to immigration, immigration policy, and immigrants themselves, as individual proclivities can differ systematically both within and across countries.

In particular, we suggest that political ideology strongly captures one's sensitivity to immigration-based threat. The empirical literature links both immigrant presence and ideological orientations with attitudes to immigration (Scheve and Slaughter 2001; Semyonov et al. 2006). For instance, in the United States, ideology and party identification are quite strongly related to anti-immigrant and anti-Latino attitudes (Hajnal and Rivera 2014). A wealth of literature demonstrates similar associations in Western Europe. The antiimmigrant position of radical right-wing parties is not only their defining feature, but also the source of their electoral appeal as these parties respond to the 'contemporary populist Zeitgeist' in the age of migration (Mudde 2007: 31; see also Betz 1993; Castles and Miller 2009; McGann and Kitschelt 2005; Norris 2005).

While ideology and party identification are undoubtedly important in explaining immigration-related attitudes, we argue that political ideology should be considered as a moderating factor rather than a direct predictor, as it conditions how individuals respond to contextual change. Ideology is often conceptualised as a personality predisposition which precedes expressed attitudes about specific political topics (Feldman and Stenner 1997; Jost et al. 2003; Kinder and Kam 2010; Stenner 2005, 2009; Wilson and Patterson 1968). A number of studies suggest that, for instance, individuals who selfidentify on the right of the political spectrum are more resistant to change and diversity (Feldman 2003; Jost et al. 2003; Stenner 2009). In this vein, scholars often treat ideological identification as a moderating variable that conditions the impact of other, more specific attitudes on policy preferences. For example, Rudolph and Evans (2005) show that political trust influences attitudes toward government spending only for individuals on the political right.

While ideological orientations are related to attitudes towards diversity, they form earlier and capture a broad underlying predisposition (Feldman and Johnston 2014). Research in political psychology shows that ideological orientations are in part due to genetic and personality features, and are thus temporally stable (Alford et al. 2005; Amodio et al. 2007; Bartels 2000). At the same time, studies show that social and political attitudes are subject to significant short-term changes (Markus 1986; Sears and Funk 1991). Attitudes towards immigrants are no exception: they change quite fluidly with media attention, the actions of political elites, and salient events involving immigrants 


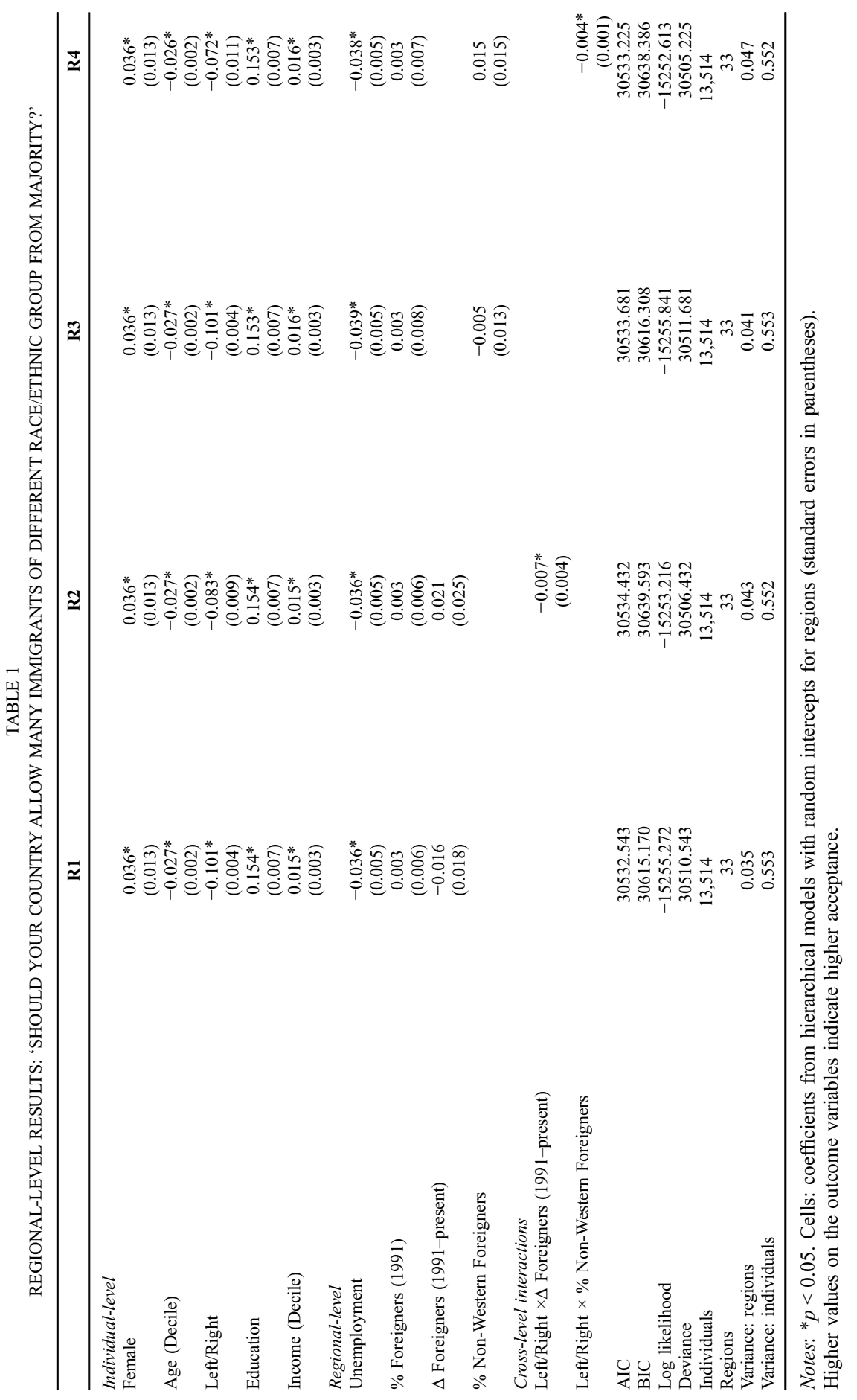


(Echebarria-Echabe and Fernandez-Guede 2006; Hopkins 2010, 2011). Thus, change in these attitudes cannot be explained by changing ideological orientations; rather, it is likely that some individuals, those especially sensitive to immigrant threat, react more strongly than others to situational triggers involving immigration.

Further, ideology itself is an imperfect predictor of attitudes. In fact, using the individual-level data presented in our empirical analysis, we find that ideology is rather weakly correlated with attitudes to immigration. As one would expect, there is a correlation between the two variables, but it is small (just above 0.2), and there are individuals on the left who report low acceptance of immigrants, as well as individuals on the right who are highly acceptant (see Figure A1 in the online appendix). Political ideology cannot be seen only as a direct cause of attitudes to immigration. Instead, we argue that those who are more sensitive to diversity - by our logic, those on the political right - will react to contextual diversity differently than those in the centre and on the left.

The presence of immigrants can stimulate at least two sources of threat that are heightened for those with a rightward ideology. First, individuals on the right espouse a conservative predisposition, eschewing change and strongly preferring stability of the status quo (Jost et al. 2003, 2007). Immigration, whether through fast-moving demographic changes or the increasingly visible presence of outsider ethnic groups, can create or intensify threat perceptions among individuals on the right. Tetlock and Mitchell (1993), for example, conjecture that political conservatives are more likely to harbour repressed hostility and to perceive a heightened sense of threat from outgroups, especially those of low socioeconomic status. Second, authoritarian personality theory argues that the cognitive orientations of conservatives are naturally linked to less tolerance of diversity and a general preference for social cohesion and uniformity (Altemeyer 1988; Feldman 2003; Feldman and Stenner 1997; Hetherington and Weiler 2009; Stenner 2005). The presence of immigrants is clear evidence of diversity, and the perceived threat will increase as the proportion of non-native residents increases, especially for those on the ideological right.

Previous non-findings or findings of weak and mixed support for the competition and contact theories are almost always based on empirical tests that do not condition natives' responses to immigration on ideological predispositions. In the United States, for example, it has been shown that diversity can stimulate both competition and contact mechanisms depending on local factors (e.g. Oliver and Wong 2003; Stein et al. 2000). There are, however, strong theoretical and empirical grounds for taking ideological orientations into consideration when analysing the effect of immigration-based threat on natives' attitudes: ideology helps determine how a particular individual will respond to the presence of immigrants. We argue that ideological orientations contribute substantially to explaining which mechanism will be more salient in natives' responses to immigrants. As immigration from culturally and economically poorer countries fosters negative attitudes by heightening the perceived threat from outgroups, the relationship between such immigration patterns and intolerance should be most 
pronounced among those on the political right. In addition, threats to the status quo arising from increasing numbers of immigrants should be perceived as stronger by those more worried about changes to the status quo - again, individuals on the political right. Following from this, we propose the following two hypotheses that build on the two threat mechanisms identified above.

H4: Recent inflows of immigrants negatively influence attitudes towards immigrants and immigration, and this negative influence is stronger for those with a rightward political ideology. [Threat to status quo mechanism, with individual moderator.]

H5: Immigration from culturally distant and economically poorer origins (as compared to those of natives) negatively influences attitudes towards immigrants and immigration, and this negative influence is stronger for those with a rightward political ideology. [Outgroup threat mechanism, with individual moderator.]

\section{Exposure and the Regional Focus}

Studying outcomes at the subnational level closely approximates to actual contact with immigrants, which is important for reflecting our theoretical argument about actual exposure. Further, subnational analyses can productively challenge conclusions reached in country-level comparative studies (e.g. Grofman and Selb 2011; Jacobs and Spierings 2010). We focus on regions in three European countries: Austria, Germany, and Switzerland.

We selected these countries in an effort to hold constant as many unobservables as possible, a virtue of 'most similar systems' designs (MSSDs). Examining a more diverse set of countries could introduce a large amount of unobserved error into the analysis, and such error is potentially not fully captured by a slew of control variables. By limiting our study to three countries that are quite similar culturally, linguistically, religiously, geographically, and economically, we are able to implicitly control for such factors, thereby decreasing the likelihood that any discovered relationships are spurious (e.g. Przeworski and Teune 1970: ch. 2). Further, because Austria, Germany, and Switzerland are among the most institutionally decentralised countries in Europe (e.g. Lijphart 2012: ch. 10), they are particularly well suited for subnational inquiry.

While MSSDs are often criticised for the inferential problems that can accompany a small number of observations and insufficient variation in key independent and dependent variables (e.g. Lieberson 1991), our subnational focus increases the number of observations and allows us to exploit a substantial range of variations in our key contextual predictors (e.g. King et al. 1994). Consequently, we can begin overcoming the drawbacks of MSSDs while largely maintaining the benefits that come with analysing 'most similar systems'. Other studies on immigration-related topics, using survey and other data, have also relied on Austria, Germany, and Switzerland (e.g. Dolezal et al. 2010; 
Gerber et al. 2010) or used individual-level data from similar, small groups of comparable countries (e.g. Ersanilli and Ruud 2011; Immerzeel et al. 2013). ${ }^{1}$

The three countries are divided into regions used for administrative and statistical purposes, namely Bundesländer (Austria and Germany) and Großregionen (Switzerland). These regions correspond to a classification of the European Statistical Office, the NUTS (nomenclature of territorial units for statistics) system. In Austria and Germany, Bundesländer consist of nine and 16 geographical subunits of the respective country. In Switzerland, Großregionen comprise seven regions. As the Swiss Federal Statistical Office notes, Großregionen are frequently used not only for regional and international comparisons, but also to reflect economic, demographic, political, and social trends toward intra-regional coordination. ${ }^{2}$ For our purpose of examining the impact of finer-grained demographic data on individual attitudes, the aspect of international comparisons is particularly useful to ensure a valid comparison between regional data from the three countries in this study.

Despite long-term efforts to harmonise demographic and other statistical data across Europe, we rely on national statistical offices for regional-level demographic information about historical immigrant presence and immigrants' countries of origin. We collect these original data because the accuracy of subnational information is crucial for testing our arguments about natives' exposure to immigrants.

To match individual survey responses to statistical information about the presence of immigrants, we benefit from the inclusion of NUTS regional identifiers in the European Social Survey (ESS). The ESS identifies respondents' residence at the level of these regions, thus offering the level of geographic granularity needed to conduct subnational analyses. This level of granularity marks an advancement beyond most other cross-national research that studies the relationship between actual immigration and attitudes. However, the regional level we use still contains large populations. Disaggregating to the smallest possible level (neighbourhood, workplace, or other social environment) would also be useful to test our argument. In the balance between generalisability and the isolation of contextual effects, our focus at the regional level in three countries maximises both. ${ }^{3}$ From a theoretical perspective, it is also important to note that individuals typically and frequently move around in a wider radius than just their neighbourhood or local community for work and leisure. Consequently, they are exposed to immigrants in a wider radius as well. Therefore, our choice of regions is not only based on the convenience of available data, but it also appropriately represents the type of exposure discussed in our argument. The variation of immigrants' presence across regions (see Figure 3) illustrates this. Recent findings from the United States reassuringly demonstrate that actual regional immigration levels are strongly related to individuals' perceptions of immigration levels (Newman et al. 2015).

Data availability restricts our analysis to 31 regions in 2002, 32 for each of 2004 and 2006, and 23 for $2008 .^{4}$ More information on these regions is available in the online appendix. For the initial country-level analyses, ${ }^{5}$ we use public 
opinion data from the European Social Survey, data on migrants from the Migration Policy Institute, ${ }^{6}$ and unemployment data from the OECD. Due to limited data on immigrants' countries of origin, we analyse 11 countries and limit these initial tests to the 2002 wave of the ESS only.

Figures 1-3 depict immigration patterns and natives' attitudes across the regions of Austria, Germany, and Switzerland. They demonstrate that both the presence of immigrants and (average) natives' attitudes vary substantially at the subnational level. ${ }^{7}$ Due to this subnational variation, we expect that national-level measures are too broad to capture the implications of our theoretical argument. We examine this by initially testing our arguments with survey data from 11 European countries before advancing to the subnational level.

\section{Data and Measurement}

Our units of analysis are native individuals. These are survey respondents who listed both of their parents as being born in their country of residence. ${ }^{8}$ All regional variables are measured in the year before the wave of the individuallevel observation.

\section{Outcome Variables}

We use two questions from the ESS that ask respondents if their country should (a) allow more immigrants of a different race or ethnic group than that of the majority or (b) allow more immigration from poorer countries. These two variables allow us to test the broader concept of attitudes toward migrants, and they correspond closely to two dimensions of immigrant characteristics that

FIGURE 1

VARIATION IN ATTITUDES TO IMMIGRATION IN 2008 (2006 FOR AUSTRIA), AVERAGES BY REGION
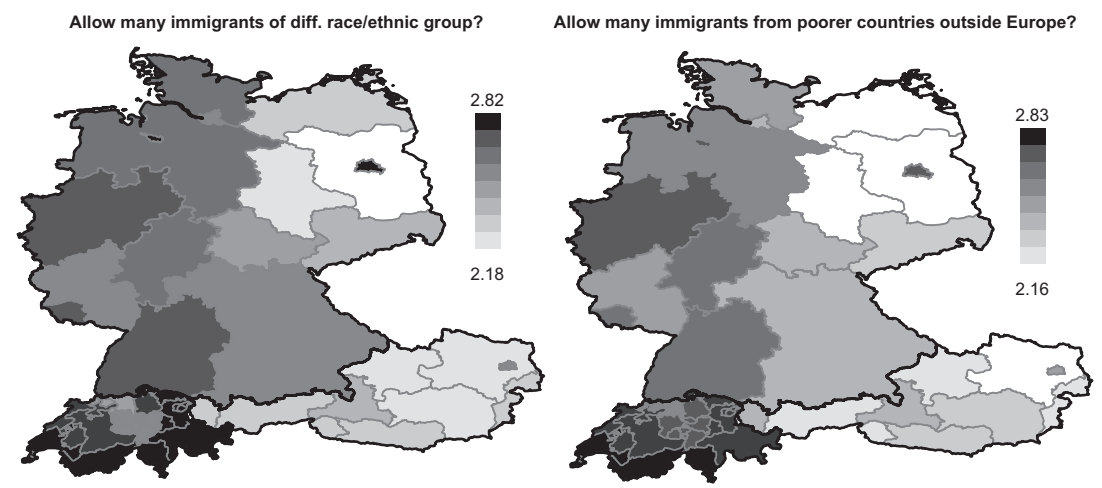

Notes: Regions are shaded based on the level of the respective variable; darker shades indicate higher relative values. White areas indicate the lowest average tolerance of immigrants, and black areas denote the highest tolerance levels among natives.

Source: European Social Survey, 2008 wave (2006 for Austria). 
FIGURE 2

VARIATION IN THE PROPORTION OF FOREIGN POPULATION BY REGION AND OVER TIME
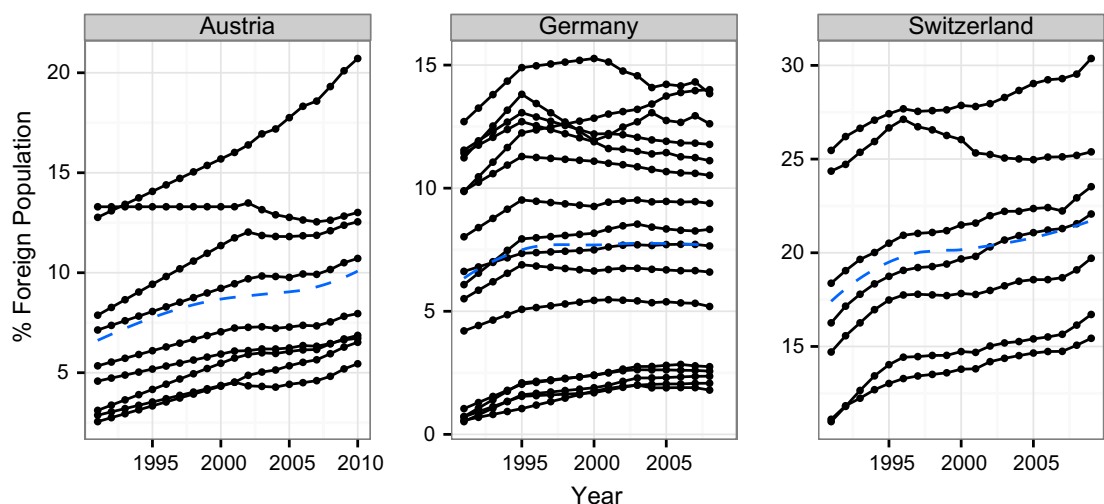

Notes: Each plot shows the proportion of foreigners in the overall population in regions (Bundesländer in Austria and Germany, Großregionen in Switzerland). The dashed lines show the smoothed average across regions for each country.

Sources: German, Austrian, and Swiss official statistics; see Table A5 in the online appendix.

may elicit threat: (a) cultural/ethnic differences and (b) economic differences. Thus, if only one type of difference drives natives' attitudes, our use of the two different questions should reveal this. The variables are measured on a fourpoint scale, with higher values indicating consent to admitting more immigrants and thus more positive attitudes toward immigrants and immigration.
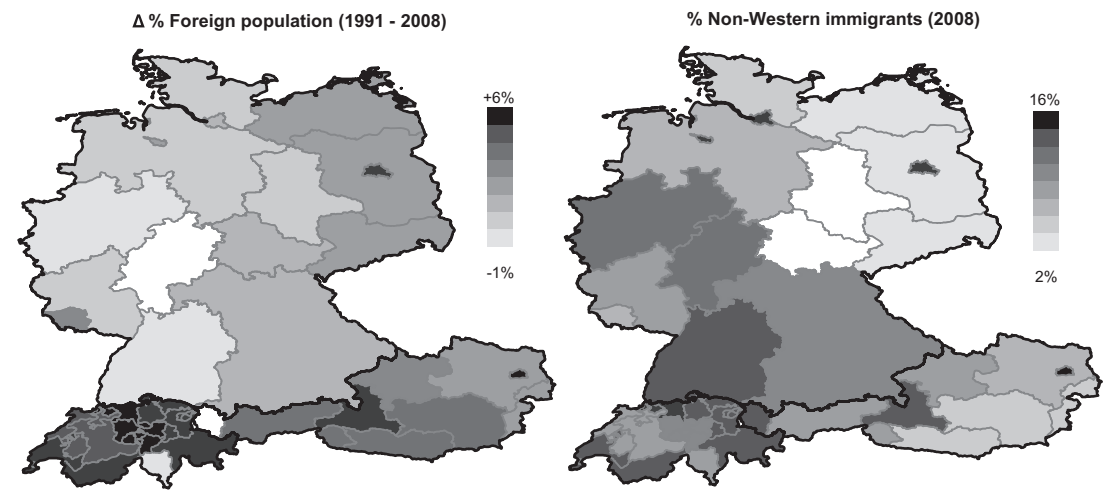

Notes: Regions are shaded based on the level of the respective variable. Darker (lighter) shades indicate growth (decrease) in the proportion of foreigners, or a higher (lower) proportion of non-Western foreigners. Sources: German, Austrian, and Swiss official statistics; see Table A5. 
Our analysis focuses on these two questions because they best approximate to the aspects of attitudes to immigration outlined in our theoretical model. If individuals feel threatened (for any reason) by migrants and display low levels of acceptance of immigrants and immigration, a primary response would be that they demand restriction on immigration. Conversely, individuals with high acceptance levels should have little to no desire to limit immigration flows. Using items that focus on opinion (such as ratings of the effect of immigration for the economy, culture, or the country in general) rather than policy revealed similar relationships to those presented in this study (see Table A19 in the online appendix).

\section{Regional-level Variables}

The key contextual explanatory variables in this study are created with newly collected data on immigration flows measured at the regional level. We use three main variables to capture immigration flows: \% Foreign (1991), $\Delta \%$ Foreign (1991-present), and \% Non-Western Foreigners. We calculated these variables based on demographic data released by the statistical offices of Austria, Germany, and Switzerland. The variable \% Foreign (1991) is the percentage of non-native individuals living in a region in the year 1991 and denotes the 'historical' stock of foreign individuals in that region, capturing the argument expressed in H1. We chose 1991 as the base year for the historical level of immigrants because that year predates migration waves of the 1990s, which brought migrants displaced by conflict (e.g. Yugoslavia, Somalia), as well as repatriations and economic migration from formerly communist states (Castles and Miller 2009). This time point thus offers a clean separation between a historical immigrant presence and more recent developments. In addition, using more recent years (1995 or 2000) as base levels returns identical findings. ${ }^{9}$ The variable $\Delta \%$ Foreign (1991-present) is the change in percentage points in the share of foreigners in a country between 1991 and the respective ESS survey year (i.e. the change from 1991 to 2002, 2004, 2006, or 2008). For instance, a region that had 6 per cent foreigners in 1991 and 9.5 per cent in 2004 receives a value of 3.5 on this variable in 2004 . This variable is used to test the argument in $\mathrm{H} 2$ and $\mathrm{H} 4$, reflecting perceived threat from changes to the status quo. ${ }^{10}$ Finally, \% Non-Western Foreigners codes the population of non-natives from all countries of origin except the EU-27 and Australia, Canada, New Zealand, and the United States. While this is an imperfect approximation of the concept of visible dissimilarity of migrants expressed in $\mathrm{H} 3$ and $\mathrm{H} 5$ (summarising visible outgroup threat) we consider the measure a notable improvement over aggregate measures of all foreigners in the extant literature. Detailed information on sources and coding of these variables is available in the online appendix (Tables A1-A5). The same coding procedures apply to the country-level data used in our initial tests. 


\section{$14 J$. Karreth et al.}

To account for economic conditions, reflecting the theoretical narrative of increased anxiety and fear of immigration under harsh economic conditions, we use the unemployment rate of the respective region or country. We estimated additional extended models that also control for regional economic wealth and the inflation rate, but omit these results from the main text to ensure comparability with the initial cross-national estimations, which are limited to fewer degrees of freedom.

\section{Individual-level Variables}

The key individual-level independent variable of interest is political ideology. A one-dimensional, left/right continuum sufficiently captures political divides across countries (Bobbio 1996; Budge et al. 2010; Gabel and Huber 2000). We thus use respondents' self-placements on a $0-10 \mathrm{left} / \mathrm{right}$ scale to measure ideology, with higher values indicating a more rightward ideology.

The remaining control variables at the individual level are standard in the literature on attitudes to immigration. Age, measured in deciles of each respondent's age in years, accounts for the finding that older individuals are, on average, thought to be more susceptible to perceived threats from increased immigration. Education, measured in five ordinal categories, captures several dynamics: possible insulation from perceived economic threat or a better grasp of the economic causes of migration; or the development of positive attitudes toward immigration through the acquisition of cosmopolitan attitudes (Hainmueller and Hiscox 2007). Household income, measured in deciles (for cross-regional comparison), also captures insulation from perceived economic threat, where wealthier respondents are less likely to consider increased immigration a threat to their source of income. Finally, a dummy variable, coded 1 for female respondents and 0 for males, is included.

\section{Method of Analysis}

Because of the nature of the argument and data - individuals nested in regions (and countries in the initial analyses), with macro-context influencing attitudes we test our hypotheses in a multilevel model framework. The equations are estimated using mixed linear models with random intercepts for each of the macro-units (regions or countries) in the sample. The base model for the test of $\mathrm{H} 1$ and $\mathrm{H} 2$ is formalised in the equation:

$$
\begin{aligned}
\text { Acceptance }_{i j}= & \beta_{0 j}+\beta_{01} \text { Female }_{i j}+\beta_{02} \text { Age }_{i j}+\beta_{03}{\text { Left } / \text { Right }_{i j}+\beta_{04} \text { Education }_{i j}} \\
& +\beta_{05} \text { Income }_{i j}+r_{i j}
\end{aligned}
$$


where $\beta_{0 j}$ is specified as:

$$
\begin{aligned}
\beta_{0 j}= & \gamma_{00}+\gamma_{01} \text { Unemployment }_{j}+\gamma_{02} \% \text { Foreign }[1991]_{j}+\gamma_{03} \Delta \% \text { Foreign }[1991 \\
& - \text { present }_{j}+u_{0 j}
\end{aligned}
$$

In these models, $\beta_{0 j}$ is the average level of the outcome variable in each macro-unit $j, \beta_{0 j}$ is predicted by the contextual factors discussed above, $u_{0 j}$ indicates the disturbance at the macro-level, and $r_{i j}$ is the error term at the individual level.

First, we consider the relationship between changes in the presence of immigrants and individual attitudes, using either $\Delta \%$ Foreign (1991-present) or \% Non-Western as measures of visible foreign presence (see Models R1 and R3 for the first outcome variable, and Models R5 and R7 for the second outcome variable). Next, we add estimates for coefficients on the cross-level interactive term between individual left/right ideology and (a) change in the presence of immigrants (Model 2 and 4) or (b) the presence of non-Western immigrants (Model 6 and 8 respectively). ${ }^{11}$

Because the outcome variables are distributed quasi-normally, we present linear model estimates in the main text to facilitate interpretation; however, separating the acceptance variable into a binary indicator of positive and negative attitudes toward immigrants returns substantively the same results (see Tables A13 and A14 and Figure A2 in the online appendix). In the regionallevel models, we also assigned random effects to 33 regions $j$ instead of 118 region-years under the assumption that our regional-level predictors sufficiently capture the variance between each of the survey waves. Auxiliary models that define the highest level as the region-year are substantively identical (see Tables A9 and A10). Finally, to capture remaining differences between different years (survey waves) and the three countries in our sample, we estimated separate intercepts (fixed effects) for each survey wave and each of the three countries in the regional analysis. Results are substantively unchanged (see Tables A11 and A12).

\section{Findings and Discussion}

Initial analyses at the country level support our assertion that the disjuncture among arguments about exposure mechanisms, attitudes, and aggregate measures of immigrant presence makes it difficult to test the hypothesised dynamics at the country level. We find evidence neither for a positive relationship between historical immigrant levels due to exposure (see Tables A7 and A8 in the online appendix), nor for the conditioning effect of natives' political ideology (see Figure 4). The data do, however, reveal an association between the increase of immigrants in a country and negative attitudes toward immigrants from poorer countries and different ethnic groups. Having demonstrated that country-level data are most likely inadequate for testing our argument (or, 
potentially, that our argument is not supported at the country level), we next discuss the findings from our subnational examinations in more detail.

The primary results of our regional analyses are presented in Tables 1 and 2 . We find some support for the threat to the status quo mechanism expressed in $\mathrm{H} 2$ : natives are less welcoming to poor immigrants in regions where the share of immigrants has recently increased (Model R5, Table 2). More importantly, the data provide evidence for the conditional mechanism expressed in our theory and summarised in $\mathrm{H} 4$ and $\mathrm{H} 5$ : negative responses to both recent increases in the numbers of immigrants and visibly different immigrants are conditional on individual political ideology.

\section{Historical Levels of Immigrant Population}

H1 expresses the expectation that long-term exposure to larger immigrant populations can induce more positive attitudes toward immigrants among natives. The regional data from Austria, Germany, and Switzerland do not support this proposition, as is evident from models R1, R3, R5, and R7 in Tables 1 and 2. This may indicate that the historical presence of migrants is less important in explaining how context affects current attitudes toward immigration, which we address in the remaining four hypotheses.

\section{Recent Changes in Immigrant Populations}

The relationship between changes in the population of foreign residents and natives' attitudes toward immigrants from poorer countries (H2) is significant and negative when considered additively (in Model R5). This supports the broader idea of increases in migration prompting a threat to the status quo for native individuals. However, the test of our conditional argument in Models R2 and R6 reveals that the role of recent changes markedly differs for individuals depending on their ideological predisposition, upon which we elaborate below.

\section{Visible Immigrant Presence}

Contrary to $\mathrm{H} 3$, the data do not indicate a statistically significant relationship between the size of the visibly different foreign population and acceptance of more migration from different ethnic groups, or from poorer non-European countries (see Models R3 and R7). Here again, our conditional argument, tested in Models R4 and R8, reveals that the effect of visibly different foreign populations varies across individuals (see below).

\section{Key Finding: Immigrant Populations and Ideological Predispositions}

Our theoretical argument proposes to resolve divergent findings on the immigration-attitude link by taking into account not just the type of immigration 


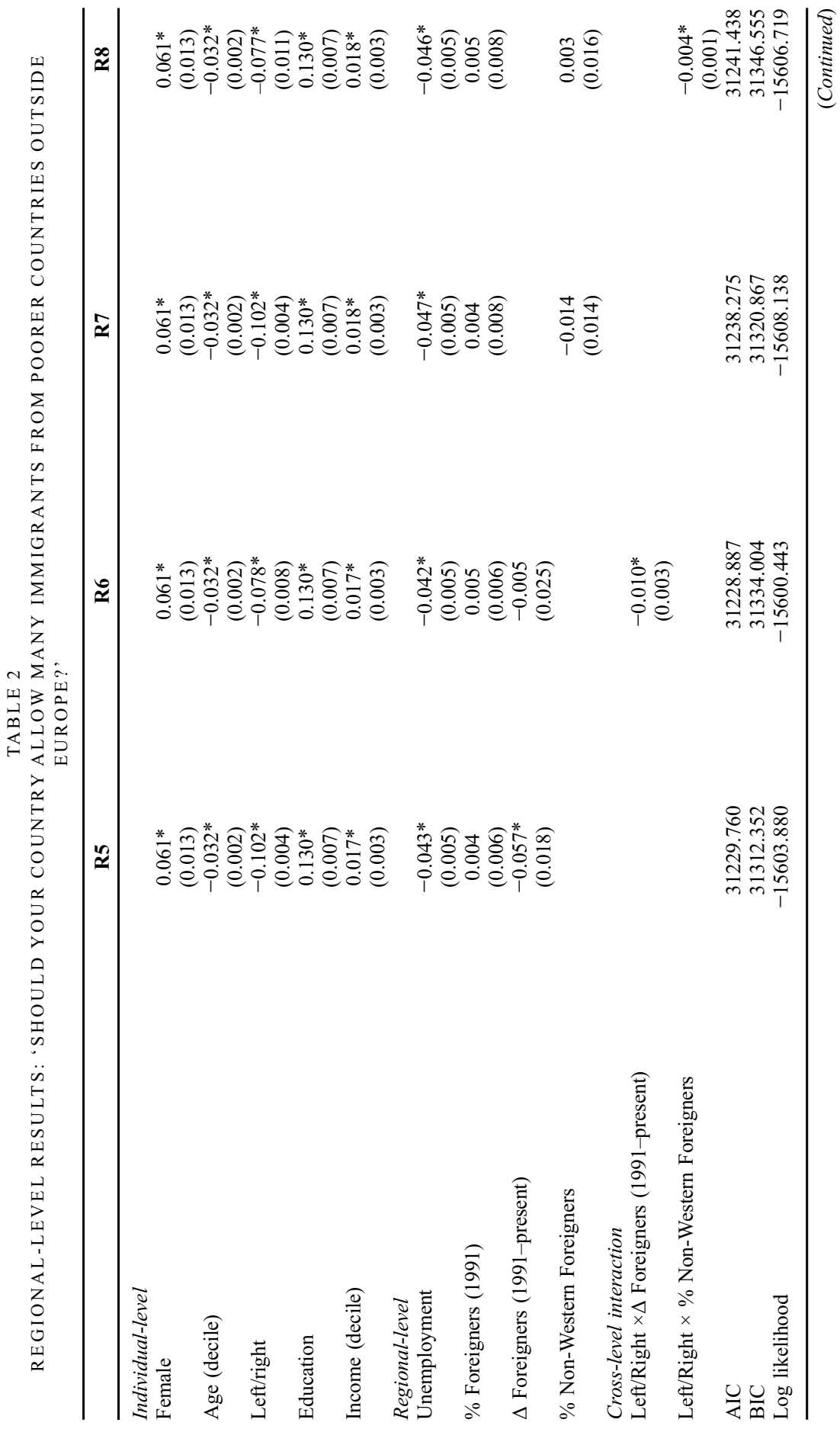


18 J. Karreth et al.

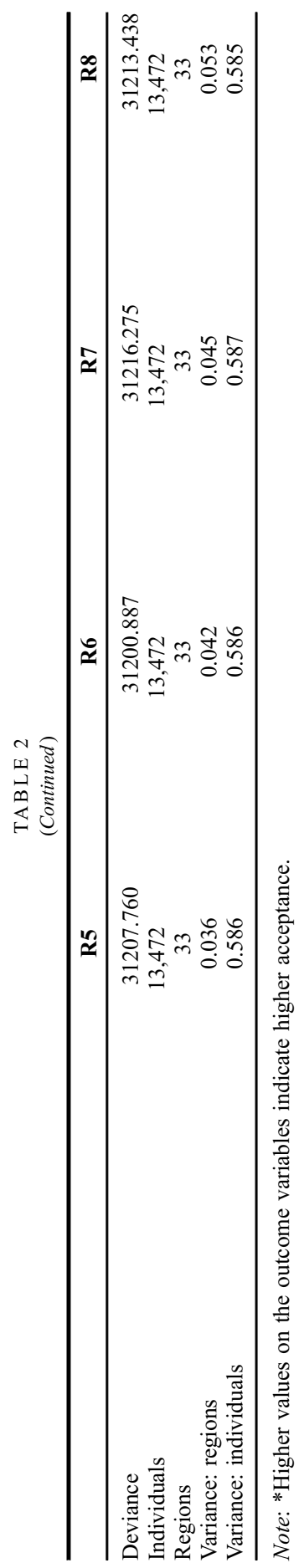


context, but also individual political predispositions. Hence, the conditional effect of recent changes in foreign population and the presence of non-Western migrants is the main focus of this analysis. Our argument specifies that the negative impact of both sudden changes in immigration levels and visible minorities on natives' attitudes is particularly pronounced for native individuals on the political right. The estimation results of Models R2, R4, R6, and R8, illustrated in Figure 5, all reflect this pattern. In Figure 5, we show how the model-based predictions of attitudes to immigration (from less accepting to more accepting) change with the context. Each of the figures shows these relationships for individuals on the political left, centre, and right. It is apparent that the relationships between the presence of immigrants and natives' attitudes are conditional on respondents' ideology, as put forth in $\mathrm{H} 4$ and $\mathrm{H} 5$.

Each panel represents one possible combination of an attitude to immigration (toward immigration from different ethnic groups, or from poorer countries) and a contextual measure of immigrants' presence (change in the proportion of foreigners, or the proportion of non-Western foreigners). In the two left-hand panels, we see no significant relationship between recent increases in immigration and attitudes for natives on the left and in the centre. However, natives on the far right report less acceptance when there are pronounced recent increases in the foreign population in their region. This relationship is statistically significant, and it is also substantial. For example, an individual on the political right is about a quarter of a standard deviation less accepting of ethnically different immigrants and about half of a standard deviation less accepting of immigration from poorer countries when he or she lives in a region that experienced a 5 percentage point increase in the population of immigrants, as compared to a region with no increase. We also see a small decline in accepting attitudes for individuals in the political centre when considering immigrants from poorer countries, but this relationship is rather small and far weaker than the relationship for those on the right.

For the presence of visibly different migrants, we find the same conditional patterns, as reflected in the two right-hand panels. All individuals that are left of centre and in the political centre are no more or less accepting of migrants whether they live in a region with more or fewer non-Western foreigners. Alternatively, for respondents on the political right, regional contexts with a higher share of non-Western foreigners are associated with a marked decrease in acceptance: about half a standard deviation of both acceptance measures in response to a 15-point increase in the percentage of non-Western foreigners.

Control variables, when significant, perform in line with the findings of the extant literature. In each comparison of models without and with the interaction terms, adding the interaction term significantly improved the model fit (at $p<0.001$ ). Further, through the inclusion of fixed effects for years and countries in Tables A11 and A12, our findings are robust to residual dynamics from temporal variance (in the form of the four survey waves) and national-level differences between the three countries, Austria, Germany, and Switzerland. 


\section{Discussion}

The results of the interactive models ( $\mathrm{R} 2, \mathrm{R} 4, \mathrm{R} 6$, and $\mathrm{R} 8$ ) provide strong support for our context-driven mechanism of threat. This is not an obvious finding. One would have good reason to expect individuals with a right-wing ideology to display relatively high levels of resentment toward immigrants no matter how many immigrants they actually encounter. A popular argument often encountered in the media has cited this dynamic when exploring the popularity of right-wing parties and activity of right-wing groups in Eastern Germany (e.g. Runge 1990; Theil 2006), where almost no foreigners live (see the white areas in the top right of Figures 1 and 3). If this were the case, we would not observe a distinct relationship between the presence of foreign populations on attitudes toward immigration among those on the right. Figure 5 does show that individuals on the political right are, across the board, less accepting of immigration, but we also find that individuals' response to context changes with individual ideological positions - and substantially so. Consequently, we recommend that the moderating role of individual predispositions be accounted for in models that examine the impact of context on attitudes to immigration in diverse settings.

Our findings improve upon recent studies considering individual and contextual sources of attitudes towards immigrants and immigration. First, our study suggests that the definition and operationalisation of contextual factors, such as different forms of immigrant presence, is important. Consistent with recent studies, we find no evidence that a higher proportion of immigrants is likely to trigger feelings of threat and produce anti-immigrant attitudes. We do, however, find robust evidence that recent and significant changes in the proportion of immigrants and the ethnic composition of immigrants matter, especially if these are measured in disaggregated, subnational territorial units (Hopkins 2010, 2011; Newman 2013).

Second, previous survey-experimental evidence (e.g. Sniderman et al. 2004) suggests that situational triggers can mobilise people to support exclusionary policies even if they do not usually hold such attitudes. While this may be the case, we find that precisely those individuals more likely to hold negative attitudes towards immigrants - those who are on the right of the political left/right scale - show intensified attitudes in contexts with large changes in immigrant proportion and a large presence of non-Western immigrants. In this way, our findings may provide additional insight into existing hypotheses on contextual effects (e.g. Hopkins 2010). This suggests that immigrant influx and national salience most likely affect natives differently depending on their political orientation.

Third, our results shed light on a finding by Semyonov et al. (2006), who show that the effects of ideological orientation on immigration-related attitudes have been increasing over time, while the effects of socioeconomic factors have remained stable. Our analyses suggest that this apparent increased explanatory power of ideology is not due to some shift in the substance of ideological orientation. Rather, it may be due to changes in the context to which respondents 
FIGURE 4

INTERACTION EFFECTS: COUNTRY-LEVEL RESULTS
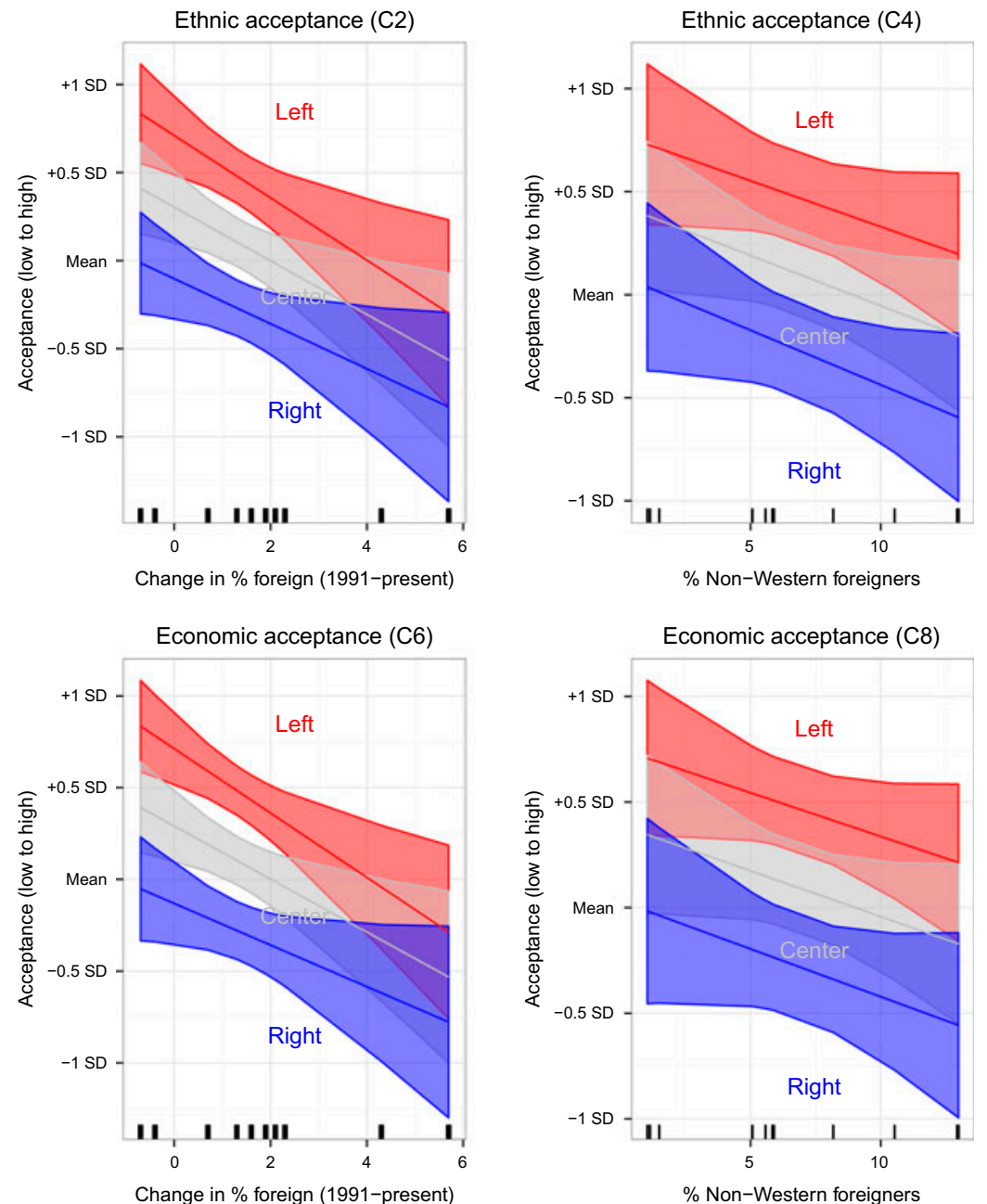

Notes: Measured at the country level, the effect of immigrants' presence on natives' acceptance of immigrants does not vary across natives' left/right self-placement. The plots display the predicted acceptance (y-axis) of immigrants from different ethnic groups or poorer countries across the range of immigrants' presence ( $\mathrm{x}$-axis) conditional on respondents' ideology. Left, centre, and right stand for values of 0,5 , and 10 on the $0-10$ left/ right self-placement scale, respectively. Effects calculated from Models C2 (top left), C4 (top right), C6 (bottom left) and C8 (bottom right), including 90\% confidence intervals. Small black vertical dashes on the $\mathrm{x}$-axis show the distribution of the observed values of the respective moderating variable. See Tables A7 and A8 in the online appendix for full results.

are subject, such as the increasing presence of immigrants and increased diversity (see Figure 2). In general, our findings underscore that examinations of the effects of individual predispositions on immigrant acceptance should not be conducted without reference to contextual conditions. 
FIGURE 5

INTERACTION EFFECTS: REGIONAL-LEVEL RESULTS (GERMANY, AUSTRIA, AND SWITZERLAND)
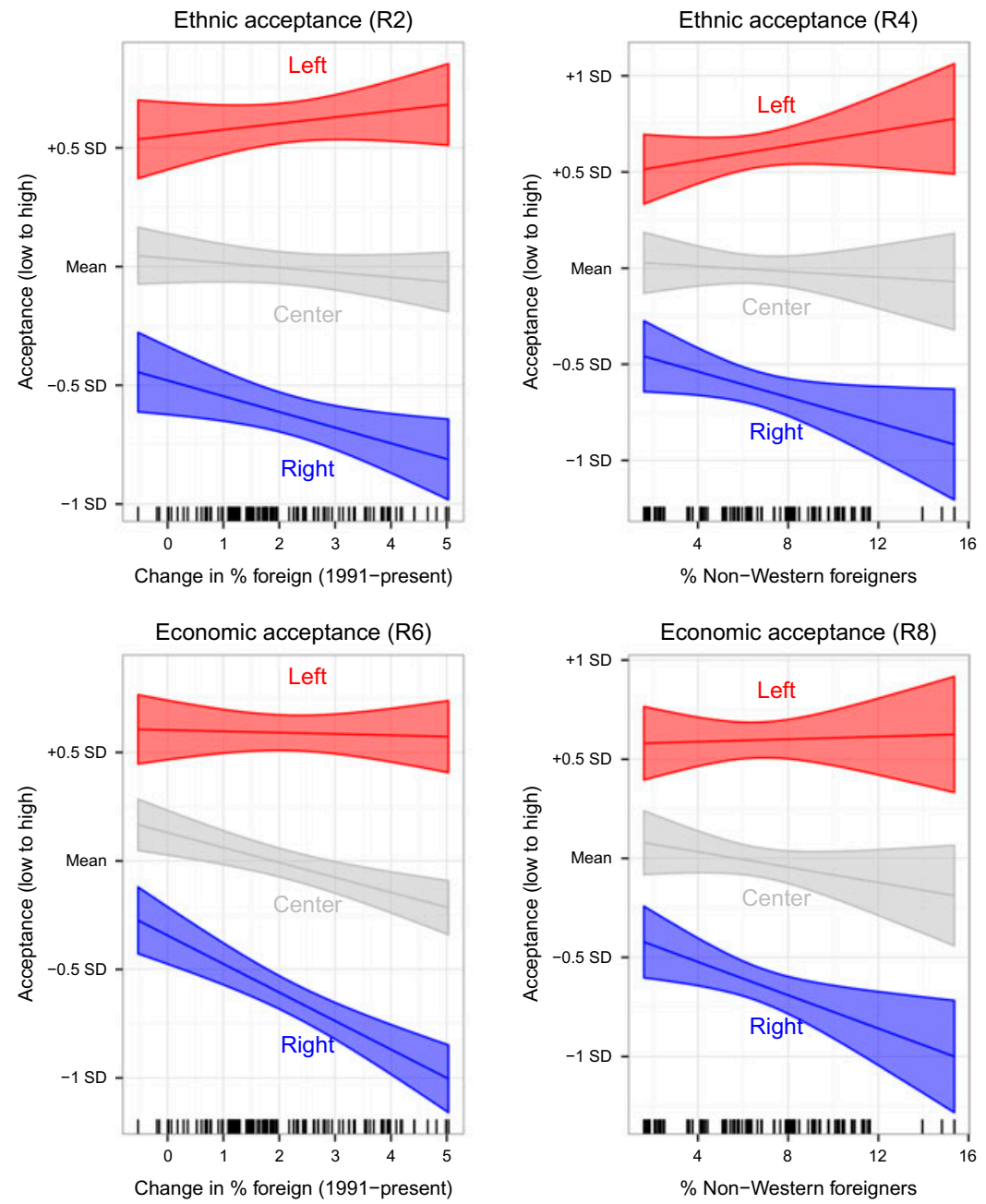

Notes: Measured at the regional level, the effect of immigrants' presence on natives' attitudes varies across natives' left/right self-placement, with a negative effect applying only to individuals on the political right. Left, centre, and right stand for values of 0,5 , and 10 on the $0-10$ left/right self-placement scale. Effects calculated from Models R2 (top left), R4 (top right), R6 (bottom left) and R8 (bottom right) in Tables 1 and 2, including $90 \%$ confidence intervals. Small black vertical dashes on the $\mathrm{x}$-axis show the distribution of the observed values of the respective moderating variable.

We also note some potential weaknesses of our study. First, while we posit that ideological orientations shape attitudinal responses to immigration, we recognise that psychological and personality-based correlates of ideology may affect such responses independent of ideology (cf. Duriez and Soenens 2006; 
Pratto et al. 2006; Stenner 2005). In this case, it would not be ideology, but rather its correlates, that condition the relationship between immigration context and attitudes. Unfortunately, data availability and space limitations prevent us from further exploring this possibility in this project.

We also recognise that ideology itself may be shaped by the immigration context. First, it is possible that individuals develop right-wing ideologies in response to proximity to immigrants or increasing immigrant populations. Second, economically mobile right-leaning individuals may migrate in response to influxes of immigrants, meaning those who are not only conservative, but also especially prone to be economically threatened by the presence of immigrants, are relatively likely to live in high-immigration regions. Bishop (2008) argues that such spatial polarisation has already taken place in the United States. Our data do not allow us to determine whether either of these dynamics are at play, and we recognise that both present a challenge to the causal pathway that we have put forth. Clever identification strategies, such as those found in the field and natural experiments of Enos (2014) and Hainmueller and Hangartner (2013), allow for a convincing account of the causal pathways between exposure to outgroups and subsequent attitudes and behaviour, and future work employing such strategies may further disentangle the relationships between immigration, ideology, and attitudes.

\section{Summary and Conclusion}

We have introduced a conditional, context-dependent argument about attitude formation in the presence of varying immigration scenarios. We test the predictions of the competition/conflict and contact theories by distinguishing between long- and short-term immigration, as well as socio-ethnic differences between immigrants and natives. We then show that both theories' predictions are more fully assessed when empirical models account for the interaction of individuallevel ideological orientations and immigrant presence. Our findings demonstrate that there is no overall negative relationship between immigration characteristics and the attitudes of natives toward immigrants; instead, such negative relationships are only present among natives on the right. These natives, who are arguably more receptive to economic and cultural threats, are relatively nonaccepting of increased immigration if they live in regions with rapidly increasing levels of immigrants or high proportions of non-Western immigrants. Thus, while the average acceptance of immigrants will vary across regions according to the character of immigration, aggregate patterns can mask the fact that attitudinal responses to migration also vary according to ideological orientations.

These findings are based on surveys of native citizens of Austria, Germany, and Switzerland. We selected these countries primarily due to research design considerations. But the conclusions drawn are also poignant in light of recent developments in each country, where immigration frequently takes the centre stage of political debates. Consider, for example, anti-immigration protest marches in Germany in 2014/15, the Swiss referenda on the construction of 
new minarets in 2009 and on a more restrictive immigration policy in 2014, and the comparatively strong presence of right-wing parties with anti-immigration platforms in the Austrian parliament in the early twenty-first century. This politicisation highlights why our findings about natives' responses to immigration can contribute to a better understanding of its broader impact on political and social dynamics: our findings imply that, where immigration is a highly politicised topic, the moderating role of ideology for individuals' responses to immigration will be particularly pronounced.

Based on our findings, we recommend that future work on attitudes toward immigrants and immigration further align theories about native-immigrant interactions with appropriate subnational measurements and account for individual-level predispositions in explaining the role of migrant presence on native attitudes. Taking the moderating effect of individual predispositions seriously could offer a number of important insights about the influence of context on attitudes beyond immigration policy, such as economic redistribution, cultural policies, and social and political tolerance in general.

\section{Acknowledgements}

We are grateful to Michael Burch, Duncan Lawrence, Anand Menon, and two anonymous reviewers for helpful comments. For research assistance, we thank Amira Jadoon and Kerri Anne Watson. A previous version of this paper was presented at the 2012 meeting of the Midwest Political Science Association.

\section{Disclosure Statement}

No potential conflict of interest was reported by the authors.

\section{Supplemental Data}

All replication data and code necessary to reproduce the analyses in this article are available at $\mathrm{http}: / /$ thedata.harvard.edu/dvn/dv/jkarreth. An online appendix is posted at http://www.jkarreth.net.

\section{Notes}

1. As far as regional-level data on immigrants and the respective regional identifiers for survey respondents are available, a replication of our study in other countries in future research would be a valuable test of the utility of a MSSD in this context.

2. See the website of the Swiss Federal Statistical Office at http://www.bfs.admin.ch/bfs/portal/de/ index/regionen/11/geo/analyse_regionen/02a.html (accessed 15 November 2014).

3. In the empirical models below, we also performed robustness checks where we accounted for additional sources of heterogeneity between these regions by controlling for population size, geographic area, and (separately) population density. None of these variables exhibited a consistent relationship with the variables of interest.

4. Due to idiosyncrasies in the Swiss population data, we created an artificial region ZürichNorthwestern Switzerland for 2002; in the years 2004, 2006, and 2008, Zürich and Northwestern Switzerland are in the sample as separate regions. Austrian responses are not 
included in the 2008 data file of the ESS; hence respondents from Austrian Bundesländer are part of our sample for the years 2002, 2004, and 2006.

5. Due to data availability, these 11 countries are Austria, Belgium, Germany, Denmark, Finland, United Kingdom, Greece, Italy, Netherlands, Norway, and Sweden.

6. Data available at http://www.migrationinformation.org/datahub/countrydata/data.cfm (accessed 13 October 2013).

7. The figures were created with immigration data we collected across the three countries and from the European Social Survey, both of which are described in detail below.

8. Eighty per cent of respondents fall into this category. This is the most specific piece of information about respondents' origin we can extract from the ESS. While it is theoretically possible that some respondents have an immigrant background despite both of their parents being born in their current country of residence, the proportion of such individuals should be so small that it would not bias our findings.

9. These results are shown in Tables A15, A16, A17, and A18 in the online appendix. Missing information on some regions for these years reduces the sample size in these models. Unfortunately, the lack of data on historical immigrant presence before 1991 for all countries in the sample prevents us from using immigrant levels from previous years for additional robustness checks.

10. Instead of using relative changes, we control for the baseline percentage of immigrants in 1991. Holding the baseline level constant allows us to make inferences about appropriately comparable changes in the presence of migrants.

11. Additional robustness checks with split samples instead of interactions return the same results (see Tables A20-A23 and Figures A3-4 in the online appendix).

\section{Notes on Contributors}

Johannes Karreth is Assistant Professor in the Department of Political Science at the University at Albany, State University of New York. His research focuses on the impact of international factors, such as international institutions and migration, on the microfoundations and outcomes of policies. His articles have appeared in journals such as the Journal of Politics, Comparative Political Studies, and Conflict Management and Peace Science.[jkarreth@albany.edu]

Shane P. Singh is Associate Professor in the Department of International Affairs at the University of Georgia. His research focuses on the institutional and contextual foundations of political behaviour and attitudes. His articles have appeared in journals such as Comparative Politics, the European Journal of Political Research, Political Research Quarterly, and the Journal of Theoretical Politics. [singh@uga.edu]

Szymon M. Stojek is a PhD candidate at the University of Georgia and a Research Assistant at the Center for Study of Global Issues (GLOBIS). His research examines how the interaction of context, interests, and values shape salient political attitudes and behavior. His articles have appeared in journals such as the Journal of Peace Research, the European Journal of International Relations, and International Studies Review. [sstojek@uga.edu]

\section{References}

Alford, John R., Carolyn L. Funk, and John R. Hibbing (2005). 'Are Political Orientations Genetically Transmitted?', American Political Science Review, 99:2, 153-67.

Allport, Gordon W. (1954). The Nature of Prejudice. Cambridge, MA: Addison-Wesley.

Altemeyer, Bob (1988). Enemies of Freedom: Understanding Right-Wing Authoritarianism.

San Francisco, CA: Jossey-Bass. 
Amodio, David M., John T. Jost, Sarah L. Master, and Cindy M. Yee (2007). 'Neurocognitive Correlates of Liberalism and Conservatism', Nature Neuroscience, 10:10, 1246-7.

Bartels, Larry (2000). 'Partisanship and Voting Behavior, 1952-1996', American Journal of Political Science, 44:1, 35-50.

Betz, Hans-George (1993). 'The New Politics of Resentment: Radical Right-Wing Populist Parties in Western Europe', Comparative Politics, 25:4, 413-27.

Bishop, Bill (2008). The Big Sort. Boston, MA: Houghton Mifflin.

Bobbio, Norberto (1996). Left \& Right: The Significance of a Political Distinction. Cambridge: Polity Press.

Boeri, Tito (2010). 'Immigration to the Land of Redistribution', Economica, 77:308, 651-87.

Bourgeois, Michael, and Noah E. Friedkin (2001). 'The Distant Core: Social Solidarity, Social Distance and Interpersonal Ties in Core-Periphery Structures', Social Networks, 23:4, 245-60.

Bowyer, Benjamin T. (2009). 'The Contextual Determinants of Whites' Racial Attitudes in England', British Journal of Political Science, 39:3, 559-86.

Brewer, Marilynn B. (2007). 'The Importance of Being We: Human Nature and Intergroup Relations', American Psychologist, 62:8, 728-38.

Budge, Ian, Lawrence Ezrow, and Michael McDonald (2010). 'Ideology, Party Factionalism and Policy Change: An Integrated Dynamic Theory', British Journal of Political Science, 40:4, 781-804.

Castles, Stephen, and Mark J. Miller (2009). The Age of Migration: International Population Movements in the Modern World, 4th ed. New York: Guilford Press.

Citrin, Jack, Donald P. Green, Christopher Muste, and Cara Wong (1997). 'Public Opinion toward Immigration Reform: The Role of Economic Motivations', The Journal of Politics, 59:3, 858-81.

Coenders, Marcel, and Peer Scheepers (2008). 'Changes in Resistance to the Social Integration of Foreigners in Germany 1980-2000: Individual and Contextual Determinants', Journal of Ethnic and Migration Studies, 34:1, 1-26.

Dolezal, Martin, Marc Helbling, and Swen Hutter (2010). 'Debating Islam in Austria, Germany and Switzerland: Ethnic Citizenship, Church-State Relations and Right-Wing Populism', West European Politics, 33:2, 171-90.

Duriez, Bart, and Bart Soenens (2006). 'Personality, Identity Styles and Authoritarianism: An Integrative Study among Late Adolescents', European Journal of Personality, 20:5, 397-417.

Echebarria-Echabe, Agustin, and Emilia Fernández-Guede (2006). 'Effects of Terrorism on Attitudes and Ideological Orientation', European Journal of Social Psychology, 36:2, 259-65.

Ellison, Christopher G., Heeju Shin, and David L. Leal (2011). 'The Contact Hypothesis and Attitudes toward Latinos in the United States', Social Science Quarterly, 92:4, 938-58.

Enos, Ryan D. (2014). 'Causal Effect of Intergroup Contact on Exclusionary Attitudes', Proceedings of the National Academy of Sciences, 111:10, 3699-704.

Ersanilli, Evelyn, and Koopmans Ruud (2011). 'Do Immigrant Integration Policies Matter? A Three-country Comparison among Turkish Immigrants', West European Politics, 34:2, 208-34.

Feldman, Stanley (2003). 'Enforcing Social Conformity: A Theory of Authoritarianism', Political Psychology, 24:1, 41-74.

Feldman, Stanley, and Christopher Johnston (2014). 'Understanding the Determinants of Political Ideology: Implications of Structural Complexity', Political Psychology, 35:3, 337-58.

Feldman, Stanley, and Karen Stenner (1997). 'Perceived Threat and Authoritarianism', Political Psychology, 18:4, 741-70.

Gabel, Matthew J., and John D. Huber (2000). 'Putting Parties in Their Place: Inferring Party LeftRight Ideological Positions from Party Manifestos Data', American Journal of Political Science, 44:1, 94-103.

Gerber, Monica M., Helmut Hirtenlehner, and Jonathan Jackson (2010). 'Insecurities about Crime in Germany, Austria and Switzerland: A Review of Research Findings', European Journal of Criminology, 7:2, 141-57. 
Grofman, Bernard, and Peter Selb (2011). 'Turnout and the (Effective) Number of Parties at the National and District Levels: A Puzzle-solving Approach', Party Politics, 17:1, 93-117.

Hainmueller, Jens, and Dominik Hangartner (2013). 'Who Gets a Swiss Passport? A Natural Experiment in Immigrant Discrimination', American Political Science Review, 107:1, 159-87.

Hainmueller, Jens, and Michael J. Hiscox (2007). 'Educated Preferences: Explaining Attitudes toward Immigration in Europe', International Organization, 61:2, 399-442.

Hainmueller, Jens, and Michael J. Hiscox (2010). 'Attitudes toward Highly Skilled and Low-Skilled Immigration: Evidence from a Survey Experiment', American Political Science Review, 104:1, 61-84.

Hajnal, Zoltan, and Michael U. Rivera (2014). 'Immigration, Latinos, and White Partisan Politics: The New Democratic Defection', American Journal of Political Science, 58:4, 773-89.

Hetherington, Marc J., and Jonathan D. Weiler (2009). Authoritarianism and Polarization in American Politics. New York: Cambridge University Press.

Hopkins, Daniel J. (2010). 'Politicized Places: Explaining Where and When Immigrants Provoke Local Opposition', American Political Science Review, 104:1, 40-60.

Hopkins, Daniel J. (2011). 'National Debates, Local Responses: The Origins of Local Concern about Immigration in Britain and the United States', British Journal of Political Science, 41:3, 499-524.

Huntington, Samuel P. (2004). Who Are We? The Challenges to America's National Identity. New York: Simon \& Schuster.

Immerzeel, Tim, Eva Jaspers, and Marcel Lubbers (2013). 'Religion as Catalyst or Restraint of Radical Right Voting?', West European Politics, 36:5, 946-68.

Jacobs, Kristof, and Niels Spierings (2010). 'District Magnitude and Voter Turnout a Multi-Level Analysis of Self-Reported Voting in the 32 Dominican Republic Districts', Electoral Studies, 29:4, 704-18.

Jost, John T., Jack Glaser, Arie W. Kruglanski, and Frank J. Sulloway (2003). 'Political Conservatism as Motivated Social Cognition', Psychological Bulletin, 129:3, 339-75.

Jost, John T., Jaime L. Napier, Hulda Thorisdottir, Samuel D. Gosling, Tibor P. Palfai, and Brian Ostafin (2007). 'Are Needs to Manage Uncertainty and Threat Associated with Political Conservatism or Ideological Extremity?', Personality and Social Psychology Bulletin, 33:7, 989-1007.

Kinder, Donald R., and Cindy D. Kam (2010). Us against Them: Ethnocentric Foundations of American Opinion. Chicago, IL: University of Chicago Press.

King, Gary, Robert Keohane, and Sidney Verba (1994). Designing Social Inquiry. Princeton, NJ: Princeton University Press.

Leiken, Robert S. (2005). 'Europe's Angry Muslims', Foreign Affairs, 84:4, 120-35.

Lieberson, Stanley (1991). 'Small N's and Big Conclusions: An Examination of the Reasoning in Comparative Studies Based on a Small Number of Cases', Social Forces, 70:2, 307-20.

Lijphart, Arend (2012). Patterns of Democracy: Government Forms and Performance in Thirty-Six Countries. New Haven, CT: Yale University Press.

Lucassen, Geertje, and Marcel Lubbers (2012). 'Who Fears What? Explaining Far-Right-Wing Preference in Europe by Distinguishing Perceived Cultural and Economic Ethnic Threats', Comparative Political Studies, 45:5, 547-74.

Markus, Gregory B. (1986). 'Stability and Change in Political Attitudes: Observed, Recalled, and ? Explained?', Political Behavior, 8:1, 21-44.

Mayda, Anna M. (2006). 'Who is against Immigration? A Cross-Country Investigation of Individual Attitudes toward Immigrants', Review of Economics and Statistics, 88:3, 510-30.

McGann, Anthony J., and Herbert Kitschelt (2005). 'The Radical Right in the Alps: Evolution of Support for the Swiss SVP and Austrian FPO', Party Politics, 11:2, 147-71.

Mudde, Cas (2007). Populist Radical Right Parties in Europe. New York: Cambridge University Press.

Newman, Benjamin J. (2013). 'Acculturating Contexts and Anglo Opposition to Immigration in the United States', American Journal of Political Science, 57:2, 374-90. 
Newman, Benjamin J., and Yamil Velez (2014). 'Group Size versus Change? Assessing Americans' Perception of Local Immigration', Political Research Quarterly, 67:2, 293-303.

Newman, Benjamin J., Yamil Velez, Todd K. Hartman, and Alexa Bankert (2015). 'Are Citizens Receiving the Treatment? Assessing a Key Link in Contextual Theories of Public Opinion and Political Behavior', Political Psychology, 36:1, 123-31.

Norris, Pippa (2005). Radical Right. NewYork, NY: Cambridge University Press.

Oliver, J. Eric, and Janelle Wong (2003). 'Intergroup Prejudice in Multiethnic Settings', American Journal of Political Science, 47:4, 567-82.

Pettigrew, Thomas F. (1998). 'Intergroup Contact Theory', Annual Review of Psychology, 49:1, 65-85.

Pettigrew, Thomas F., and Linda R. Tropp (2008). 'How Does Intergroup Contact Reduce Prejudice? Meta-analytic Tests of Three Mediators', European Journal of Social Psychology, 38:6, 922-34.

Pratto, Felicia, Jim Sidanius, and Shana Levin (2006). 'Social Dominance Theory and the Dynamics of Intergroup Relations: Taking Stock and Looking Forward', European Review of Social Psychology, 17:1, 271-320.

Przeworski, Adam, and Henry Teune (1970). The Logic of Comparative Social Inquiry. New York: Wiley-Interscience.

Quillian, Lincoln (1995). 'Prejudice as a Response to Perceived Group Threat: Population Composition and Anti-Immigrant and Racial Prejudice in Europe', American Sociological Review, 60:4, 586-611.

Rudolph, Thomas J., and Jillian Evans (2005). 'Political Trust, Ideology, and Public Support for Government Spending', American Journal of Political Science, 49:3, 660-71.

Runge, Irene (1990). 'East Germany: A People Who Tolerate Intolerance', Los Angeles times, July 29, 1990.

Scheve, Kenneth F., and Matthew J. Slaughter (2001). 'Labor Market Competition and Individual Preferences over Immigration Policy', Review of Economics and Statistics, 83:1, 133-45.

Schlueter, Elmar, and Ulrich Wagner (2008). 'Regional Differences Matter: Examining the Dual Influence of the Regional Size of the Immigrant Population on Derogation of Immigrants in Europe', International Journal of Comparative Sociology, 49:2-3, 153-73.

Schneider, Silke L. (2008). 'Anti-Immigrant Attitudes in Europe: Outgroup Size and Perceived Ethnic Threat', European Sociological Review, 24:1, 53-67.

Sears, David O., and Carolyn L. Funk (1991). 'The Role of Self Interest in Social and Political Attitudes', in Mark P. Zann (ed.), Advances in Experimental Social Psychology, Vol. 24. San Diego, CA: Academic Press, 1-91.

Semyonov, Moshe, Rebeca Raijman, and Anastasia Gorodzeisky (2006). 'The Rise of Anti-Foreigner Sentiment in European Societies, 1988-2000', American Sociological Review, 71:3, 426-49.

Sherif, Muzafer, O.J. Harvey, B. Jack White, William R. Hood, and Carolyn W. Sherif (1961). Intergroup Conflict and Cooperation: The Robbers Cave Experiment. Norman, OK: University Book Exchange.

Sides, John, and Jack Citrin (2007). 'European Opinion about Immigration: The Role of Identities, Interests and Information', British Journal of Political Science, 37:3, 477-504.

Sniderman, Paul M., Louk Hagendoorn, and Markus Prior (2004). 'Predisposing Factors and Situational Triggers: Exclusionary Reactions to Immigrant Minorities', American Political Science Review, 98:1, 35-49.

Stein, Robert M., Stephanie Shirley Post, and Allison L. Rinden (2000). 'Reconciling Context and Contact Effects on Racial Attitudes', Political Research Quarterly, 53:2, 285-303.

Stenner, Karen (2005). The Authoritarian Dynamic. New York: Cambridge University Press.

Stenner, Karen (2009). 'Three Kinds of "Conservatism”', Psychological Inquiry, 20:2-3, 142-59.

Tajfel, Henri (1981). Human Groups and Social Categories. New York: Cambridge University Press. 
Tetlock, Philip E., and Gregory Mitchell (1993). 'Liberal and Conservative Approaches to Justice: Conflicting Psychological Portraits', in B. Mellers and J. Baron (eds.), Psychological Perspectives on Justice: Theory and Applications. New York: Cambridge University Press, 234-56.

Theil, Stefan (2006). 'Germany: See No Evil, Say No Evil - Why Can't Germans Talk Honestly about the Hate in the East?', Newsweek, June 5, 2006.

Wagner, Ulrich, Oliver Christ, Thomas F. Pettigrew, Jost Stellmacher, and Carina Wolf

(2006). 'Prejudice and Minority Proportion: Contact instead of Threat Effects', Social Psychology Quarterly, 69:4, 380-90.

Welch, Susan, and Lee Sigelman (2000). "Getting to Know You? Latino-Anglo Social Contact', Social Science Quarterly, 81:1, 67-83.

Wilson, Glenn D., and John R. Patterson (1968). 'A New Measure of Conservatism', British Journal of Social and Clinical Psychology, 7:4, 264-9.

Wright, Stephen C., Arthur Aron, Tracy McLaughlin-Volpe, and Stacy Ropp (1997). 'The Extended Contact Effect: Knowledge of Cross-Group Friendships and Prejudice', Journal of Personality and Social Psychology, 73:1, 73-90.

Zolberg, Aristide R., and Long Litt Woon (1999). 'Why Islam is like Spanish: Cultural Incorporation in Europe and the United States', Politics and Society, 27:1, 5-38. 